\title{
As Políticas Públicas para o Desenvolvimento do Território Médio Rio das Contas: Potencialidades e Desafios
}

\author{
João Sotero do Vale Júnior ${ }^{\text {; }}$ Ionara Menezes de Alencar Gondim ${ }^{2}$; Juliana Bispo dos Santos ${ }^{3}$; \\ Carolina Maria Itaparica Nascimento Neves ${ }^{4}$
}

Resumo: A divisão da Bahia em Territórios de Identidade é um dos temas desta pesquisa. Essa política pública do Estado da Bahia tem apresentado bons resultados ao identificar potencialidades e pontos de convergência entre os municípios baianos. O presente estudo tem como objetivo geral estudar as políticas públicas de fomento à economia criativa para o Território Médio Rio das Contas. O aporte teórico foi sustentado Souza (2006); Fonseca (2009); Lambertucci, (2009); Rodrigues (2011); Ministério da Integração, (2004) dentre outros. Trata-se de um artigo teórico-empírico, de caráter exploratório, qualitativo, que utilizou o método descritivo. Nos resultados, sugerimos como política pública para os municípios dos Territórios baianos que apoiem os movimentos populares (econômicos, artístico-culturais, identitários, etc.). A criação de comissões permanentes de diálogo com a população e seus representantes; buscar o apoio dos governos estadual e federal; capacitar a população para captar recursos através de editais existentes em apoio à cultura e economia.

Palavras-chave: Políticas Públicas. Território de Identidade. Economia Criativa.

\section{Public Policies for the Development of the Middle Territory Rio das Contas: Potentials and Challenges}

\begin{abstract}
Anstract: The division of Bahia into Identity Territories is one of the themes of this research. This public policy of the State of Bahia has presented good results in identifying potentialities and points of convergence among the municipalities of Bahia. The present study has the general objective to study the public policies to promote the creative economy for the Rio das Contas Middle Territory. The theoretical contribution was sustained Souza (2006); Fonseca (2009); Lambertucci, (2009); Rodrigues (2011); Ministry of Integration, (2004) among others. It is a theoretical-empirical article, exploratory, qualitative, that used the descriptive method. In the results, we suggest as a public policy for the municipalities of the Bahian Territories to support popular movements (economic, artistic, cultural, identity, etc.). The creation of permanent commissions of dialogue with the population and their representatives; seek the support of state and federal governments; empower the population to raise funds through existing bids in support of culture and economy.
\end{abstract}

Keywords: Public Policies. Territory of Identity. Creative economy.

\footnotetext{
${ }^{1}$ Administrador. Mestre em Administração pela Universidade Salvador - UNIFACS. Pesquisador Gestão da Educação, Aprendizagem Organizacional e Inovação - GEDAI. Docente da Pós-Graduação Latu-sensu em Gestão Pública da Faculdade de Tecnologia e Ciências, Unidade Jequié, Bahia, Brasil, joao.sotero.js@gmail.com.

${ }^{2}$ Administradora. Discente da Pós-Graduação Latu-sensu em Gestão Pública da Faculdade de Tecnologia e Ciências, Unidade Jequié, Bahia, Brasil, yonaramenezes@hotmail.com.

${ }^{3}$ Administradora. Discente da Pós-Graduação Latu-sensu em Gestão Pública da Faculdade de Tecnologia e Ciências, Unidade Jequié, Bahia, Brasil, julianajolly91@gmail.com.

${ }^{4}$ Administradora. Discente da Pós-Graduação Latu-sensu em Gestão Pública da Faculdade de Tecnologia e Ciências, Unidade Jequié, Bahia, Brasil, carollmaria@hotmail.com.
} 


\section{Introdução}

Por muito tempo, as políticas públicas do Estado se voltaram mais para a capital e região metropolitana, havendo pouca valorização do interior e regiões menos desenvolvidas. Entretanto, nos últimos anos, os municípios distantes das capitais vêm se tornando cada dia mais visíveis, através de planejamentos governamentais que são fundamentados pelas necessidades de autonomias e identidade das regiões, principalmente as de características prioritariamente rurais.

Voltar a morar no interior e conquistar a tão sonhada qualidade de vida, tem sido a busca de muitas pessoas que deixaram as suas cidades pelo êxodo rural ou pela falta de oportunidades nas cidades interioranas. Tal procura deve-se ao aumento da população humana, e a grande concentração dessa população em grandes centros urbanos, à forma e ao ritmo da ocupação desses espaços e ao modo de vida com base na produção e consumo cada vez mais rápidos de bens, a violência, a desigualdade social, o desemprego, causando um caos urbano e o desinteresse em viver nesses locais. Mas, como tudo tem os dois lados, essa decisão é pautada por algumas diretrizes e uma delas é a oportunidade de gerar a sua renda, o seu sustento, o seu trabalho. Já no caso dos habitantes dessas pequenas cidades, a cultura, a criação e muitas às vezes a falta de opção ou criatividade, faz com que a busca por ganhar o pão seja praticamente baseada na atividade local da sua região.

É salutar reforçar que o desafio dos últimos tempos é desenvolver as cidades a partir de ações criativas e sustentáveis, onde envolva, principalmente, a relação entre gestão pública e privada. Algumas iniciativas já em curso empenham-se em construir alternativas socioeconômicas sustentáveis, assumindo um compromisso com um modelo de desenvolvimento que consiga integrar a sustentabilidade econômica, social, ambiental e cultural, contribuindo assim para o aprimoramento do próprio ser humano, ganhando na riqueza dos relacionamentos e no convívio social comunitário.

Toda iniciativa econômica ou cultural deve partir do princípio que os Estados, Cidades e Municípios, são espaços geográficos ocupados por uma sociedade pensante e criativa em que devem predominar decisões pautadas na democracia e no diálogo.

O desenvolvimento territorial tem se tornado, recentemente, um dos métodos adotados pelo governo do estado da Bahia na promoção de políticas de desenvolvimento. Esse processo 
de organização social deve respeitar as peculiaridades de cada território, identificar os principais desafios, bem como buscar alternativas de desenvolvimento existentes com base em seus potenciais e no bem-estar da população. A implantação dos "territórios da cidadania e de identidade" é um marco dessa estratégia, na medida em que tem como objetivo articular o direcionamento de recursos e programas oriundos de diferentes ministérios para os territórios que receberem tais apoios de políticas públicas. A estrutura montada para tal objetivo envolve a construção, em cada território, de "conselhos intermunicipais" formados por membros da comunidade local.

Entretanto, é observado que a participação popular nas Gestões Públicas ainda é tímida e muitos gestores optam por gerir sozinhos os recursos já existentes, recebidos através dos programas Federais e Estaduais e planejam como investir esses recursos, deixando de buscar novas atividades geradoras de receitas para os municípios diminuindo, dessa forma, as oportunidades de crescimento e desenvolvimento local de forma vertical.

A exploração do potencial criativo do ponto de vista econômico vem sendo destacado como o caminho para o desenvolvimento territorial em municípios da Bahia, através de políticas públicas direcionadas para a economia criativa incitando estudos pela área acadêmica e pelos órgãos governamentais. Nesse sentido, as questões de pesquisa deste estudo são: quais as políticas públicas voltadas para os territórios de identidade da Bahia? Como a economia criativa tem contribuído para o desenvolvimento dos Territórios, especialmente o Médio Rio das Contas?

Além disso, este estudo tem o intuito de destacar a possibilidade do desenvolvimento da Economia Criativa como política pública em regiões com diversidade, potencialidade e carência de soluções viáveis e criativas para o desenvolvimento regional, especialmente na área econômica. Destacamos algumas iniciativas bastante criativas adotadas em alguns municipios do Território de Identidade do Médio Rio das Contas.

\section{Políticas Públicas para o Desenvolvimento de Territórios}


Políticas públicas são conjuntos de programas, ações e decisões tomadas pelo governo (nacional, estadual ou municipal) que visam assegurar determinados direitos e de cidadania para vários grupos da sociedade ou para determinado segmento social, cultural, étnico ou econômico, às vezes, tais medidas contam com a participação, direta ou indireta, de entes públicos ou privados.

Segundo Souza (2006), das diversas definições e modelos sobre políticas públicas, onde podemos extrair e sintetizar seus elementos principais:

a) A política pública permite distinguir entre o que o governo pretende fazer e o que, de fato, faz.

b) A política pública envolve vários atores e níveis de decisão, embora seja materializada através dos governos, e não necessariamente se restringe a participantes formais, já que os informais são também importantes.

c) A política pública é abrangente e não se limita a leis e regras.

d) A política pública é uma ação intencional, com objetivos a serem alcançados.

e) A política pública, embora tenha impactos no curto prazo, é uma política de longo prazo.

f) A política pública envolve processos subsequentes após sua decisão e proposição, ou seja, implica também implementação, execução e avaliação.

Todo governante, em quaisquer esferas de poder, precisa traçar em seu plano de governo políticas que norteiem seu trabalho e que, de fato, saia do papel. Conforme afirma Souza (idem), elas devem ser abrangentes e exequíveis, que se concretizem em ações práticas e em benefício da sociedade. Nem sempre é possível que essas políticas deem resultado imediatamente, por isso, o planejamento, essencial para qualquer atividade, precisa ser pensado a curto, médio e longo prazo.

As políticas públicas repercutem na economia e nas sociedades, daí por que qualquer teoria da política pública precisa também explicar as inter-relações entre Estado, política, economia e sociedade (ibidem). Essas quatro instâncias indubitavelmente estão relacionadas entre si. As sociedades evoluíram ao longo do tempo e sentiram a necessidade de se organizar em estados, nações cujos representantes devem [ou deveriam] representar o desejo da população. A política é o grande amálgama que liga o Estado à sociedade que, por sua vez, deposita naquele todas as suas expectativas, inclusive com relação à vida privada (políticas sociais) e econômica. 
Cabe ao Estado trabalhar para que a economia seja conduzida da melhor forma possível. Sabemos que a política neoliberal defende que o ente público interfira o mínimo possível na economia, entretanto, o Estado precisa agir, sim, como moderador do mercado, caso contrário, o consumidor pode ser prejudicado se o capital não for administrado a favor do povo, especialmente em favor dos menos favorecidos.

Os elementos principais que definem políticas públicas são as ações que o governo pretende fazer para atender as demandas da população a quem ele representa. Não obstante, a participação da população nem sempre é requerida, principalmente quando o ente público precisa tomar as chamadas "medidas impopulares". Fonseca (2009) destaca, porém, que é preciso haver um "canal" de conexão entre a administração e a população, a fim de se garantir o êxito das políticas públicas. Segundo essa autora,

Para que as experiências de democracia participativa obtenham êxito, as administrações municipais têm papel fundamental, através da criação de canais de interconexão que viabilizem a integração entre governo e dos diversos segmentos da sociedade, especialmente a população de menor renda. De tal maneira, que possam ser partícipes das diversas fases do processo de planejamento e de deliberação das Políticas Públicas a serem implementadas nas cidades (FONSECA, 2009, p. 34).

Num plano utópico, a população seria sempre ouvida e teria suas aspirações atendidas, mas, infelizmente, sabemos que nem sempre ocorre desta maneira, o que é um equívoco, visto que,

\begin{abstract}
A participação social [...] amplia e fortalece a democracia, contribui para a cultura da paz, do diálogo e da coesão social e é a espinha dorsal do desenvolvimento social, da equidade e da justiça. Acreditamos que a democracia participativa revela-se um excelente método para enfrentar e resolver problemas fundamentais da sociedade brasileira. (LAMBERTUCCI, 2009, p. 71)
\end{abstract}

A participação social é considerada importante elemento de gestão e componente fundamental para a elaboração das políticas públicas. As propostas do programa de governo são [ou devem ser] construídas a partir das demandas e necessidades da sociedade. Essas, na medida do possível, são incorporadas às políticas públicas (idem).

As políticas públicas em si, não são suficientes para modificar a realidade social, para tanto, alguns elementos são requeridos, principalmente, a existência de atores políticos com capacidade para diagnosticar e analisar a realidade social, econômica e política em que vivem, 
aptos também para negociar de maneira democrática com os diferentes indivíduos ${ }^{5}$ envolvidos no processo. Obviamente, não é uma tarefa fácil, pois, "tudo isso envolve habilidades para gerenciar complexidades (em cenários de incertezas e turbulência, por exemplo) e conseguir colaboração de todos os que estão envolvidos na implementação de determinadas ações de governo" (RODRIGUES, 2011, p. 25). Em quaisquer situações, o bem comum deve ser o principal alvo, em detrimento de preferências/vantagens pessoais.

\title{
Territórios de Identidade: Uma nova forma de Organização do Território Baiano
}

A despeito dos problemas ainda enfrentados pelo Brasil, podemos observar que políticas públicas voltadas para o desenvolvimento do país têm sido adotadas, ainda que em ritmo menos acelerado do que gostaríamos, e a população começa a sentir as melhorias advindas do governo federal, estadual e municipais. O agrupamento regional em Territórios de Identidade é uma dessas novidades, objeto de estudo deste trabalho, e que, se bem entendido e aplicado surtirá efeitos positivos. O Decreto $\mathrm{n}^{\circ} 12.354$ publicado no Diário Oficial do Estado da Bahia em 25 de agosto de 2010, em seu art $1^{\circ}$, assim define o Território de Identidade:

\begin{abstract}
$\S 1^{\circ}$ - Considera-se Território de Identidade o agrupamento identitário municipal formado de acordo com critérios sociais, culturais, econômicos e geográficos, e reconhecido pela sua população como o espaço historicamente construído ao qual pertence, com identidade que amplia as possibilidades de coesão social e territorial.
\end{abstract}

Dessa forma, o governo estadual visa garantir maior isonomia na adoção de políticas públicas para os municípios baianos, objetivando atender as demandas territoriais e, assim, diminuir as diferenças socioeconômicas no estado. Além disso, buscando também promover a implementação de políticas públicas e ações de desenvolvimento para a Bahia, o Executivo estadual, para fins de planejamento, adotou uma nova classificação de território, atendendo a uma orientação do Ministério da Integração, com vistas a diminuir as diferenças regionais:

\footnotetext{
${ }^{5}$ No processo de elaboração de políticas públicas é extremamente necessária a participação da população, pois os programas governamentais serão construídos conforme as necessidades expostas pelos envolvidos, destacando as reais necessidades social, econômica e politica.
} 
Pode-se observar, no nosso país, a presença de regiões de alta renda com potencial dinâmico, assim como de regiões estagnadas e com baixos níveis de renda. A questão regional, na atualidade, abrange todo o território nacional e demanda um olhar mais acurado sobre as realidades sub-regionais. As desigualdades regionais brasileiras constituem um enorme obstáculo ao desenvolvimento do país, conspirando contra a construção de uma Federação solidária e progressista. Por um longo tempo, o país deixou de influir de forma planejada no desenvolvimento de suas regiões, resultando no aprofundamento de índices de desigualdades que causam transtornos sociais agudos e acirram movimentos regionais desfavoráveis ao desenvolvimento sustentável do país (MINISTÉRIO DA INTEGRAÇÃO, 2004).

Assim, considerando aspectos sociais, econômicos e culturais, o governo dividiu o Estado da Bahia em 27 territórios de identidade:

Imagem 01: Mapa da Bahia com as divisões dos 27 Territórios.

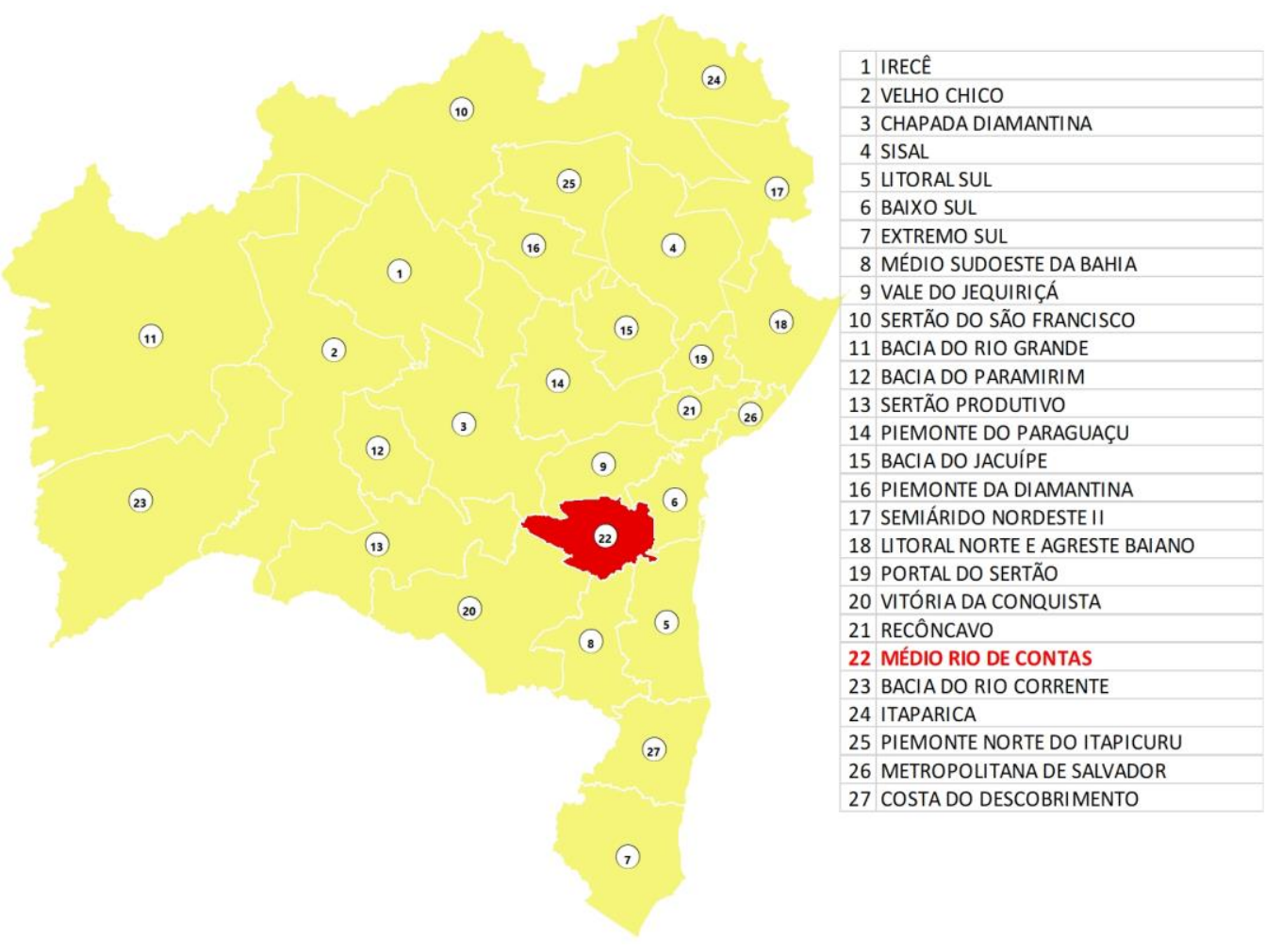

Fonte: imagem elaborada pelos pesquisadores com base em dados. 
Entender a noção de território é algo relevante, principalmente se considerarmos as dimensões continentais do país, assim como do estado da Bahia, igualmente extenso, comparado a outros como Sergipe, por exemplo. Segundo Bahia (2017),

\begin{abstract}
O território é conceituado como um espaço físico, geograficamente definido, geralmente contínuo, caracterizado por critérios multidimensionais, tais como o ambiente, a economia, a sociedade, a cultura, a política e as instituições, e uma população com grupos sociais relativamente distintos, que se relacionam interna e externamente por meio de processos específicos, onde se pode distinguir um ou mais elementos que indicam identidade, coesão social, cultural e territorial.
\end{abstract}

Ao incorporar a dimensão territorial como parte da estratégia de desenvolvimento, o modelo de gestão social poderá ser capaz de se adequar à situação específica de cada território, de modo a responder com efetividade aos desafios encontrados em meio à complexidade, extensão e diversidade do Estado. A adoção dos Territórios de Identidade foi um grande avanço para o planejamento público, pois, não apenas revela e considera toda a diversidade (cultural, ambiental, econômica e social) existente no estado, como também estabelece um novo paradigma na formulação das políticas públicas, tão importantes para o desenvolvimento social, econômico e cultural como um todo.

\title{
Território de Identidade Médio Rio das Contas
}

O Território de Identidade do Médio Rio das Contas (TMRC), que tem como composição geográfica a macrorregião do semiárido baiano, compreende uma área de 9.903,7 $\mathrm{km}^{2}$, equivalente a $1,8 \%$ do território do estado e engloba 16 municípios, Aiquara, Apuarema, Barra do Rocha, Boa Nova, Dário Meira, Gongogi, Ibirataia, Ipiaú, Itagi, Itagibá, Itamari, Jequié, Jitaúna, Manoel Vitorino, Nova Ibiá e Ubatã. A sua população é de 366.507 mil habitantes. O território é caracterizado por ampla diversidade climática, ambiental e cultural. O percentual da população extremamente pobre, em 2010, foi de 14,3\%. O Rio das Contas, que batiza o território, é de importância fundamental para a subsistência e as atividades econômicas exercidas no Médio Rio das Contas. Entre os usos destacam-se o abastecimento, a irrigação, a mineração e a geração de energia (Barreto et al, 2014). 
O Território de Identidade Médio Rio das Contas possui como principais arranjos produtivos rurais a caprinocultura/ovinocultura e os cultivos de café e de mandioca. A caprinocultura/ovinocultura é bastante primitiva nessa região. O arranjo é executado de forma extensiva e configura uma atividade predominantemente familiar, se dividindo com outras atividades.

O patamar tecnológico observado está direcionado para a produção de carne e produção leiteira. O cultivo de café é realizado de forma incipiente e sem grande mecanização e insumos muito modernos. O cultivo de mandioca é realizado de forma elementar e como produção para subsistência. Este arranjo não configura uma atividade especializada. (Barreto et al, 2014).

Em 2015 a Secretaria de Desenvolvimento Rural do Estado, lançou o perfil sintético do Território de Identidade do Médio Rio das Contas onde destacou:

O Território de Identidade Médio Rio das Contas tem 10 mil estabelecimentos agropecuários com Agricultura Familiar, segundo levantamento do Censo Agropecuário 2006 do IBGE. Desse total, as maiores quantidades localizam-se em Manoel Vitorino (1,3 mil), seguido de Jequié (1,2 mil) e Jitaúna (1,1 mil). Os municípios com os menores números de estabelecimentos com Agricultura Familiar no território são Gongogi (124) e Barra do Rocha (160).

Quando se trata do mercado de trabalho no Território Média de Rio de Contas o Censo do Instituto Brasileiro de Geografia e Estatística - IBGE, relata um grande índice de desemprego. Principalmente nas comunidades rurais, com renda inferior ao salário mínimo atual. Vejamos os dados:

O Mercado de Trabalho no Médio Rio de Contas evidencia algumas situações precárias. Uma delas é que os trabalhadores sem carteira assinada são maioria em relação àqueles que são formalizados (46,1 mil contra 40,1 mil). O rendimento médio, porém, é inferior: os primeiros recebiam R\$ 841, contra R\$ 707 dos trabalhadores informais (IBGE, 2010).

A vulnerabilidade fiscal desses municípios, com baixa capacidade de receitas próprias, tornava-os mais vinculados a programas sociais do governo federal, principalmente para custeio de educação, saúde, saneamento básico e investimentos em infraestrutura. As receitas próprias eram insuficientes para a execução de políticas públicas que pudessem melhorar a qualidade de vida da população. 
A partir da análise dos indicadores socioeconômicos observa-se que existe uma desigualdade intrarregional. Essa disparidade econômica e social entre os municípios do território caracteriza-se por apresentar municípios com melhores índices, como Jequié e Ipiaú que se destacam como polos econômicos e com Índice de Desenvolvimento Humano - IDH superiores, e os demais municípios com problemas relacionados, principalmente, à má distribuição de renda. Assim, se faz necessário pensar formas e alternativas de incremento das políticas públicas no sentido de atender a esta realidade, sobretudo no que se refere aos indicadores renda e educação (PTDSS, 2016)

Segundo Almeida (2012 apud SOUZA, 2015, p. 23), uma vez detectado o potencial de determinada região em função de suas características estruturais, identificam-se também os setores econômicos que, se fomentados, podem dinamizar as atividades econômicas regionais, pois essa análise tende a contribuir com as discussões sobre o desenvolvimento regional e setorial a partir da economia criativa que pode ser praticada tanto a nível individual como coletivo (associações, cooperativas, etc.).

\section{A Economia Criativa}

Nos últimos anos a exploração do potencial criativo do ponto de vista econômico, vem sendo destacada como o caminho para o desenvolvimento socioeconômico pela área acadêmica e pelos órgãos governamentais através de políticas públicas para Economia Criativa.

Segundo Reis (2008, p. 16), o conceito de economia criativa origina-se do termo indústrias criativas, por sua vez inspirado no projeto Creative Nation, da Austrália, de 1994. Dentre outros elementos, este defendia a importância do trabalho criativo, sua contribuição para a economia do país e o papel das tecnologias como aliadas da política cultural, dando margem à posterior inserção de setores tecnológicos no rol das indústrias criativas.

Partindo de uma análise da produção bibliográfica pioneira a respeito da economia criativa, nota-se que esta era marcada pelo foco em indústrias criativas e em sua dinâmica econômica. A profusão de interpretações conceituais não sugere uma linha comum. Caves, por exemplo, entende por indústrias criativas as relacionadas a artes, cultura e entretenimento 
em geral (CAVES, 2000). Já para Howkins o divisor de águas da economia criativa seria o potencial de gerar direitos de propriedade intelectual (segundo o autor, a "moeda da economia criativa"), expandindo sua abrangência dos direitos autorais para desenhos industriais, marcas registradas e patentes. Sob essa defi - nição torna-se difícil dizer o que não integraria a economia criativa na sociedade contemporânea e qual diferenciação apresentaria frente à economia do conhecimento. (HOWKINS, 2001)

Segundo o relatório ${ }^{6}$ de atividades da Superintendência de Desenvolvimento da Economia do Estado de Mato Grosso (2015-2016) a economia criativa não se resume a uma alternativa ou diversificação da economia tradicional, mas uma renovação poderosa e transformadora nos tempos atuais. Esse modelo de negócio origina-se através das atividades de diversos setores, também no desenvolvimento de produtos ou serviços vindos do principal gerenciador potencial, o conhecimento, a criatividade ou capital intelectual que produzem bens tangíveis e intangíveis, com conteúdo criativo e valor econômico.

Além dos benefícios econômicos para pequenas e grandes cidades, a economia criativa contribui significativamente para o desenvolvimento social e urbano, com baixos custos de investimentos, e podendo ser desenvolvida a qualquer momento que se deseje, respeitando-se o devido planejamento. A grande vantagem é o potencial para gerar bem-estar, autoestima e qualidade de vida em indivíduos e comunidades, por meio de atividades prazerosas e representativas das características de cada localidade, estimula o crescimento inclusivo, de fomento e sustentável (BORGES, 2016, p. 14).

Nessa conjuntura, as cidades criativas conformariam o espaço territorial onde as atividades criativas e inovadoras se desenvolvem, dado que, por um lado o espaço urbano é produtor de indivíduos e atividades criativas, e por outro, é produtor dos consumidores dessas atividades e produtos criativos (HOSPERS, 2003 apud CATELA, 2016).

\section{Presença da Economia Criativa no Território de Identidade Médio Rio de Contas}

O Território Médio Rio de Contas (TMRC) apresenta várias potencialidades econômicas. Dentre as 16 cidades que o compõe (Aiquara, Apuarema, Barra do Rocha, Boa

\footnotetext{
${ }^{6}$ Disponível em:< http://mtcriativo.mt.gov.br/images/RELATORIO_Economia_Criativa.pdf> Acessado em 02/04/2017. 
Nova, Dário Meira, Gongogi, Ibirataia, Ipiaú, Itagi, Itagibá, Itamari, Jequié, Jitaúna, Manoel Vitorino, Nova Ibiá e Ubatã), algumas vêm se destacando nos últimos anos, como polos de desenvolvimento econômico em que a criatividade tem possibilitado avanços consideráveis nos campos econômico e social. Vale ressaltar que a parceria Estado-Município é de suma importância para o sucesso das políticas públicas voltadas para os territórios.

A seguir apresentamos uma tabela com as potencialidades das cidades do TIMRC e algumas de suas atividades econômicas:

Tabela 01: Potencialidades dos Municípios

\begin{tabular}{|c|c|}
\hline MUNICÍPIO & POTENCIALIDADES \\
\hline Aiquara & Cacaicultura e agricultura familiar. \\
\hline Apuarema & Agricultura familiar, pecuária. \\
\hline Barra do Rocha & Turismo rural, artesanato. \\
\hline Boa nova & $\begin{array}{l}\text { Turismo sustentável e atrativos naturais (Cachoeiras, área de proteção ambiental, turismo } \\
\text { ecológico.) }\end{array}$ \\
\hline Dário Meira & Turismo rural (Rio Gongogi, bares, fazendas etc.), cacauicultura. \\
\hline Gongogi & Agricultura familiar, agronegócios. \\
\hline Ibirataia & $\begin{array}{l}\text { Artesanato e turismo rural (Cores da terra, restaurante beija flor cachaça engenho Bahia, } \\
\text { fazenda lajedo do ouro, fazenda Solar das Águas.) }\end{array}$ \\
\hline Ipiaú & $\begin{array}{l}\text { Patrimônio cultural, turismo rural e eventos (Fazenda Laurena, parque de exposição José } \\
\text { Tiara, antigo Cine Éden, implantação do Centro de Cultura, festival de chocolate, cachaça } \\
\text { jequitibá) }\end{array}$ \\
\hline Itagi & Turismo rural (cachoeiras, fazendas), agricultura familiar. \\
\hline Itagiba & $\begin{array}{l}\text { Espaços culturais e Fabricação de destilados. (Cachaça Itagibá, grupo Baviera, festas } \\
\text { populares, Mineradora Mirabela.) }\end{array}$ \\
\hline Itamari & Agricultura familiar, pecuária. \\
\hline Jequié & $\begin{array}{l}\text { Espaços culturais, turismo rural (Centro de cultura, praça do artesanato, teatro, parque de } \\
\text { exposição, festas populares, economia solidaria.) }\end{array}$ \\
\hline Jitaúna & Comércio, agricultura familiar, turismo rural (fazendas, cachoeira), Festejos de São Pedro. \\
\hline Manoel Vitorino & Agricultura familiar, turismo rural. \\
\hline Nova Ibiá & Agricultura familiar, pecuária. \\
\hline Ubatã & Comércio, agricultura, cacauicultura. \\
\hline
\end{tabular}

Fonte: tabela elaborada pelas pesquisadoras com base em dados observados no cotidiano das referidas cidades.

Conforme podemos observar na tabela acima, há em todas as cidades que compõem o Território Médio Rio das Contas potencialidades a serem exploradas/incentivadas. Os exemplos citados não encerram todas as possibilidades, são apenas amostras de atividades da 
economia criativa que podem ser desenvolvidas nos municípios citados, principalmente se houver o implemento de políticas públicas que fomentem a economia criativa.

\section{Metodologia}

Trata-se de um artigo teórico-empírico, de caráter exploratório, qualitativo, que utilizou o método descritivo. O estudo teórico-empírico utiliza-se de um quadro de referência teórico e através da coleta e análise de dados tenta afirmá-lo ou negá-lo no todo ou em parte. É exploratório, porque visa promover ao pesquisador um maior conhecimento sobre o tema ou problema de pesquisa em perspectiva (MATTAR, 1994).

O foco principal da abordagem qualitativa está em compreender, descrever e interpretar os significados que as pessoas projetam no fenômeno estudado. Compara-se a teoria já estabelecida com os resultados empíricos da observação de campo. Esta preocupação torna-se relevante por acreditar-se que o processo pelo qual uma pessoa concebe uma realidade, atribuindo-lhe significado, confirma suas ações e decisões. Utiliza-se de método descritivo, porque expõe as características de determinado fenômeno, sem, no entanto, comprometer-se em explicar os fenômenos que descreve, embora possa servir de base para tal explicação. Pela sua natureza de sondagem, não comporta hipóteses prévias que, todavia, poderão surgir durante a análise ou ao final da pesquisa (VERGARA, 1990).

O método adotado para a coleta de dados foi a elaboração de um questionário contendo 05 questões objetivas direcionado para 02 funcionários de diferentes níveis hierárquicos do Território de Identidade do Médio Rio das Contas, concentrado no Munícipio de Jequié-BA, cidade que polariza esse território. Os questionários foram aplicados no mês de julho de 2017.

No que se refere à amostra, foram 02 entrevistas. A escolha dos 02 participantes foi feita por serem representantes do Território e por, supostamente, terem conhecimento acerca do assunto. Por questões de ética, não divulgaremos os nomes dos entrevistados e nem seus respectivos cargos e locais de trabalho. Ao citar suas respostas, os denominaremos apenas como Entrevistado 1 (E1) e Entrevistado 2 (E2). 
A aplicação do questionário para funcionários de diferentes níveis hierárquicos, objetivou entender a percepção deles no que se refere a composição do poder organizacional dentro da instituição. Com isso foi possível avaliar como essa instituição estabelecem as relações das políticas públicas para o desenvolvimento da economia criativa dentro da sua estrutura organizacional.

\section{Resultados e Discussões}

Após essas breves considerações acerca da política dos Territórios de Identidade e da economia criativa, aplicamos um questionário com sete perguntas (em anexo) a dois funcionários ligados a repartições do TIMRC a fim de averiguar o que estes conhecem sobre a economia criativa e verificar se há políticas públicas voltadas para a economia criativa no Território de Identidade Médio Rio das Contas. Para fins de organização e melhor compreensão das entrevistas dividimos as respostas ao questionário em três dimensões: Economia criativa, Potencialidades e Implantação de atividades.

\section{Economia Criativa}

Nesta primeira dimensão trabalharemos o conceito de economia criativa, pois sabemos que não é algo novo, mas não temos um conceito bem definido e exclusivo. Durante a pesquisa perguntamos aos entrevistos o que é "Economia Criativa"? e vamos analisar os conceitos originados pelos entrevistados E1 e E2:

\footnotetext{
"São atividades econômicas geradas a partir da habilidade intelectual, cultural e criativa do individuo e que gera valor, ocupação e renda, diversidade cultural e desenvolvimento humano. É característica da economia criativa, além da capacidade intelectual, o domínio da criação, o controle da produção e a logística destes bens e/ou serviços." (E1);

"Eu acho que a economia ela é muito ampla e a gente a todo o momento está trabalhando a Economia Criativa, a gente que é voltada para a classe pequena, para o pequeno produtor, para o artesão, para as pessoas da Economia Solidaria de modo geral, a gente está a todo momento envolvido com isso e buscando alternativa que possa fortalecer a economia dessas pessoas que são muitas pessoas que estão dentro
} 
desse processo e se a gente não pensar em uma organização para que eles possam ir se fortalecendo, a gente não tiver esse olhar de não poder ajudar a organização, a gente vai passar um grande período sem poder ver pessoas em uma situação de melhorias." (E2)

Embora a resposta do E1 seja mais sucinta que a do E2, ambos convergem no sentido de que a economia criativa parte de atitudes individuais e são geradoras de divisas. Outro ponto de comum acordo entre os entrevistados é que, apesar de a economia ser fruto da criatividade humana, nem tudo pode ser considerado como economia criativa (pergunta 2 do questionário.). Eles concordam que as atividades decorrentes desse tipo de economia são setoriais e podem [e devem] ser implementadas pelo poder público, pois, “[...] nem toda economia é considerada economia criativa, ela é um setor da economia, e a partir dai como ela é necessária estimular nas pessoas, estimular a criatividade com fins econômicos, que venham gerar renda, empregos, e desenvolvimentos.” (E2)

O entendimento acerca do que é a economia criativa é um fator importante para o desenvolvimento para os Territórios, visto que, a partir de uma visão clara acerca do tema, os responsáveis pela criação de políticas públicas voltadas para esse tipo de economia poderão fomentar os setores que trabalham sobre esse viés, principalmente os microempreendedores, artesão, pequenos produtores etc. que podem contribuir para o desenvolvimento socioeconômico regional.

\section{Potencialidades}

$\mathrm{Na}$ segunda dimensão visamos identificar quais potencialidades no TIMRC, frente ao processo de Economia Criativa. Fizemos a seguinte pergunta aos entrevistados: O Território do Médio Rio das Contas, já levantou em pesquisa as potencialidades criativas dos municípios?. Vejamos as respostas dos entrevistados:

\footnotetext{
“Como economia criativa não. No ano de 2016, realizamos o levantamento de potencialidades e demandas territoriais à elaboração do Plano Territorial de Desenvolvimento Rural Sustentável e Solidário - PTDRSS Médio Rio das Contas.” (E1)

"Olha, a gente vem algum tempo trabalhando essas potencialidades, com apoio de diversas secretarias, já tivemos aqui, a construção do diagnostico com a visita de
} 
representantes das secretarias do governo do estado. A gente vem se envolvendo há muito tempo, vem fazendo as nossas feiras da agricultura familiar, tem sempre um espaço para os artesões, para as pequenas agroindústrias, a gente sabe que o caminho é esse, tem que se organizar e fortalecer esses segmentos que são pessoas que realmente precisam de ajuda. A gente sabe que o grande gargalo deles é a comercialização. Se a gente não organizar esse setor, sabemos que ele vai ficar muito tempo nisso e o nosso território tem sido um marco nessa questão das ideias de fortalecer esse segmento.” (E2)

A relativa divergência nas respostas não pode ser vista como um problema, posto que os entrevistados respondem por diferentes setores do Território de Identidade Médio Rio das Contas. Enquanto o E1 relata que participou do levantamento das potencialidades e demandas para elaboração do Plano Territorial de Desenvolvimento Rural Sustentável e Solidário PTDRSS Médio Rio das Contas, o E2 afirma que já há um esforço para o fomento da economia criativa na região:

[...] A gente vem se envolvendo há muito tempo, vem fazendo as nossas feiras da agricultura familiar, tem sempre um espaço para os artesões, para as pequenas agroindústrias, a gente sabe que o caminho é esse, tem que se organizar e fortalecer esses segmentos que são pessoas que realmente precisam de ajuda. [...]" (idem)

Segundo a fala dos entrevistados e a nossa observação pessoal, podemos afirmar que o Território de Identidade Médio Rio das Contas tem avançado nas políticas públicas voltadas para a economia criativa contribuindo, dessa forma, para o fortalecimento da região. Infelizmente, nem todas as cidades do Território estão no mesmo patamar que algumas cidades citadas aqui como exemplo (Boa Nova, Ipiaú, Itagibá e Jequié), mas podem também ter suas economias favorecidas se seus representantes atentarem para as suas potencialidades e nelas investir com políticas públicas adequadas à cada realidade.

Dando continuidade a entrevista aferimos que seria necessário compreender quais as potencialidades atrativas dos municípios. Onde levamos ao questionamento: Quais são os potenciais atrativos dos municípios da região que mais fortalecem a implantação da Economia Criativa, como política de desenvolvimento econômico e social.

“O artesanato produzido nos municípios de Ibirataia, Dário Meira, Jequié, Manoel Vitorino, Itagibá e Ipiaú. Nestes municípios são produzidos produtos tendo como matéria prima: o retalho de tecido, a madeira extrativista, o corte/costura, a palha, entre outros materiais." (E1); 
"Nossa potencialidade maior está na nossa economia a cacauicultura, [...]. Hoje para colher o cacau, não se beneficia direito, se vende ele pelo peso, e ele não vai desenvolver a sua função [...], esse é o grande desafio nosso, a gente vem discutindo isso há algum tempo, já estamos indo para o nosso $5^{\circ}$ Agrocacau e $3^{\circ}$ Festival de Chocolate, mas buscando sempre esse objetivo, e que esse é um trabalho do anseio do produtor. Tivemos o primeiro seminário em 2012, ainda na extensão do parque de exposição, e o encaminhamento dos produtores foram esses, a gente vem trabalhando, e ainda talvez não seja nem a nossa geração que possa ver isso acontecer, mas tem um grande consciência dos produtores, que já podemos ver, mas a não ser isso, [...] Bom então, como eu estava falando, isso tem uma amplitude muito grande e a gente como atua nesses 16 municípios e nós temos diversas potencialidades, em Manuel Vitorino além de ter essa grande potencialidade do município maior produtor de umbu do Brasil, nós temos também uma gama de artesões, eles começam a produzir o artesanato, e vende ali na beira. Esse pessoal a gente tem buscando muito, a gente sabe que esses artesões são artistas valiosos, o município de Boa Nova, nós temos também lá, pessoas interessantíssimas que produz artesanato, temos também Dário Meira, Itagi, tem artesões que fazem trabalhos magníficos, em Aiquara, tem um pintor que faz pinturas de forma excepcional, temos as nossas feiras, onde damos oportunidades, para todas essas pessoas, buscando apoiar e valorizar, já foi ideia do Território a gente construir um espaço para fortalecer a comercialização de todos esses produtos. A ideia é que fosse a Manuel Vitorino ou em Jequié, e a gente através do Governo conseguisse um galpão dentro de um espaço adequado próximo a BR para que a gente pudesse oportunizar a exposição desses produtos todos, não só dos produtos alimentícios, mas a pintura, os artesões de modo geral com seus produtos, acha que isso ainda é um objeto, que a gente tem como prioridade nossa, mas temos que esperar o momento certo, o governo vem com suas dificuldades, vem com suas burocracias, mas como a gente entende que isso é um caminho não vamos desistir desse trabalho." (E2)

Conforme podemos observar nessas respostas, o potencial regional é enorme. Os entrevistados apresentaram vários exemplos que demonstram que se a economia atingir, digamos assim, um nível criativo, nesse território, poderá trazer grandes benefícios. Um bom exemplo dado foi o do cacau vendido in natura, que "[...] hoje para colher o cacau, não se beneficia direito, se vende ele pelo peso, e ele não vai desenvolver a sua função [...]” (E2), ou seja, se em vez de vender a matéria prima, houvesse incentivos para se vender o chocolate e outros derivados do cacau, o valor agregado seria bem maior, gerando mais divisas para os produtores e, consequentemente, aquecimento da economia local e melhoria de vida para muitas pessoas beneficiadas direta ou indiretamente. 


\section{Implantação de Atividades da Economia Criativa}

Nessa perspectiva, chegamos à terceira dimensão desta análise, a questão da implantação de atividades. Uma das perguntas-chave desta seção foi: Existe algum projeto de política pública para implantação da atividade da economia criativa no território? Considerando as respostas fornecidas, podemos inferir que essa é uma política ainda incipiente. O E1, respondendo a esse questionamento, afirmou que

"Não. Considerando que a política territorial surge a partir dos territórios rurais e que a base econômica do nosso território é rural, trabalhamos com o conceito de Desenvolvimento Territorial, assim, atividades da economia criativa ficam inseridas neste contexto." (E1)

Considerando a diversidade do TIMRC, sabemos que projetos de políticas públicas para implantação [e fortalecimento] da economia criativa, poderia contribuir muito para o crescimento econômico de nossa região, sobretudo naqueles municípios em que há pouca movimentação econômica. O E2 também corrobora com a resposta do E1 quando afirma que não há políticas específicas para esse fim. Entretanto, ele apresenta uma visão bem otimista sobre o atual panorama:

\footnotetext{
"Olhe, políticas públicas voltadas especificas, eu até não conheço, a gente sabe que tem editais muitos editais que a gente pode agregar esse setores criativos, a gente já teve aqui oportunidade de editais da cultura, fomentando esse pessoal de pequenas instituições culturais, que envolve a verdadeira cultura, a questão do bumba meu boi, da mulinha de ouro, essas atividades culturais de modo geral, o terno de reis. Também a gente constrói diante de edital desses a aquisição de alguns implementos, o próprio Bumba Meu Boi, você consegue comprar materiais para essas estruturas, até mesmo para as filarmônicas buscando participação para implementos para filarmônicas, as vezes também a gente incentiva através de um Pronaf ${ }^{7}$, a compra de uma estrutura, um acordeom, mostrando que esses talentos que existem no interior, ele pode ser estimulado através de um política publica que não dirigida para isso, mas você abre um leque para que se oportunize isso, é um talento que está naquela coisa. Eu já fiz um financiamento de um Pronaf para as pessoas adquirirem uma guitarra, um violão, um acordeom, são políticas que a gente pode se beneficiar para esse setor, mas a gente precisa abrir o leque para isso.” (E2)
}

Conforme afirmamos acima, embora não haja ainda políticas específicas para a implantação de atividades da economia criativa, muito já tem sido feito, especialmente no que diz respeito à cacauicultura:

\footnotetext{
${ }^{7}$ Programa de Fortalecimento da Agricultura Familiar 
“[...] a própria verticalização do cacau é uma economia criativa, a gente está tentando organizar a base dos pequenos produtores, para que a gente possa verticalizar esses produtos, a do umbu, já foi a quebra desse tabu, os catadores do umbu já fazem a sua produção. Até a gente tornar essa coisa em realidade, precisaremos passar por muita coisa ainda... A gente precisa muito das lideranças, dos gestores das pessoas que possam entender e se unir fortemente para fortalecer." (E2)

E2 aponta também como alternativa a essa deficiência a existência de editais como o Pronaf como paliativos, que podem servir para incentivar as atividades da economia criativa já existentes no Território. Nesse sentido, acreditamos que os órgãos locais (prefeituras, câmaras, entidades filantrópicas, etc.) poderia capacitar os pequenos empreendedores, agricultores, artistas e produtores em geral para participarem de determinados editais de fomento à agricultura familiar, à cultura local, dentre outro, visto que, nem sempre, as pessoas envolvidas nessas atividades estão preparadas para concorrer a um edital.

Enfim, é preciso "identificar o setor da economia criativa, trabalhar o conceito de economia criativa no território; criar uma rede de atividades econômicas e organizar a distribuição e a logística dos bens e serviços da economia criativa. Simples assim! ”(E1).

\section{Considerações Finais}

A Economia Criativa refere-se à capacidade de criar, reinventar, diluir paradigmas tradicionais, unir pontos desconexos e equacionar soluções para novos e velhos problemas. É um termo utilizado para nomear modelos de negócios, empreendimentos ou gestão que originam em atividades, produtos ou serviços desenvolvidos a partir do conhecimento, criatividade ou capacidade intelectual de indivíduos visando à criação de emprego e renda. Através da valorização do simbólico, da cultura e das raízes, a economia criativa/solidária preconiza o desenvolvimento local.

Políticas para a economia criativa precisam responder não somente às necessidades econômicas, mas também às demandas especiais das comunidades locais, relacionadas à educação, identidade cultural, desigualdades sociais e questões ambientais. Um número cada vez maior de municípios em todo o mundo está empregando o conceito de cidades criativas para formular estratégias de desenvolvimento urbano a fim de revigorar o crescimento com 
foco em atividades culturais e criativas. Os principais princípios podem ser adaptados para as áreas rurais e comunidades menos favorecidas, como uma ferramenta de geração de empregos, especialmente para a juventude, fortalecimento das mulheres criativas e promoção da inclusão social de uma forma alinhada com o alcance dos Objetivos de Desenvolvimento do Milênio. Dessa forma, os municípios estão agindo com mais rapidez e perspicácia do que as esferas de governos federais, que podem se tornar mais restritas por conta de burocracias e questões de poder. Idealmente, planos de ações de metas para a economia criativa devem ser moldados em todos os níveis, desde a esfera comunitária até a municipal e a federal, independentemente da ordem. Contudo, é importante reconciliar objetivos culturais e sociais com instrumentos de comércio, tecnologia e turismo (Relatório de economia criativa 2010).

Conforme observamos neste estudo, o reconhecimento de cada Território de identidade permitiu que o governo conhecesse melhor as dificuldades e potencialidades de cada região e, sobretudo, a adoção de políticas públicas voltadas para o potencial de cada região. Os exemplos aqui mencionados corroboraram para demonstrar que é possível gerar renda e desenvolvimento mesmo nos menores municípios, explorando o potencial cultural e econômico de cada lugar. Observamos também que as populações têm atuado de forma criativa na economia local e que o apoio dos poderes públicos é essencial para o fortalecimento do Território e o desenvolvimento da economia criativa, essencial para o desenvolvimento de cidades onde a indústria é pequena ou inexistente.

As entrevistas feitas nos permitiram observar ainda que, embora não haja uma política específica para a criação de atividades da economia criativa, existem sim políticas públicas voltadas para a economia criativa, mais desenvolvida em alguns setores e incipientes em outros. Mas o reconhecimento público da importância das atividades da economia criativa e as políticas adotadas até o presente momento têm demonstrado que o Estado está trabalhando para o fortalecimento dos Territórios de Identidade.

Por fim, sugerimos como política pública para os municípios dos Territórios baianos que apoiem os movimentos populares (econômicos, artístico-culturais, identitários, etc.). A criação de comissões permanentes de diálogo com a população e seus representantes também é uma alternativa viável, além de se buscar o apoio dos governos estadual e federal, assim como capacitar a população para captar recursos advindos dos vários editais existentes em apoio à cultura e economia. 


\section{Referências}

ALMEIDA, E. Econometria espacial aplicada. Campinas, SP: Editora Alínea, 2012. In: SOUZA, Thiago Cavalcante de. A dinâmica e os efeitos de transbordamento da economia criativa no nordeste do Brasil. Ilhéus, BA: UESC, 2015. 180 f. (Dissertação de Mestrado)

BAHIA. Territorialização da Cultura. Disponível em: < https://territoriosculturaisbahia.wordpress.com/divisao-territorial/> Acessado em 02/05/2017.

BARRETO, R. M. (org.) Bahia 2000-2013. São Paulo : Editora Fundação Perseu Abramo, 2014. 152 p.: il. ; $23 \mathrm{~cm}$ - (Estudos Estados Brasileiros).

CAVES, R. Creative Industries. Harvard: Harvard University Press, 2000

FONSECA, J. F. R. O Orçamento Participativo e a Gestão Democrática de Goiânia. Dissertação (Mestrado em Desenvolvimento e Planejamento Territorial). Programa de PósGraduação em Desenvolvimento e Planejamento Territorial da Universidade Católica de Goiás. Goiânia, 2009.

HOWKINS, J.. The Creative economy - How people make money from ideas. London: Penguin Books, 2001.

HOSPERS, G. Creative Cities: Breeding Places in the Knowledge Economy, Knowledge, Technology, \& Policy, Vol. 16, №. 3, pp. 143-162, 2003. In: CATELA, Eva Yamila da Silva. O potencial criativo das cidades brasileiras: uma análise multidimensional. Espacios. Vol. 37 (N 12) Año 2016. Pág. 12

LAMBERTUCCI, A. R.. A participação social no governo Lula. In: AVRITZER, Leonardo (org.). Experiências nacionais de participação social. São Paulo: Cortez, 2009. (Coleção Democracia Participativa)

MINISTÉRIO DA INTEGRAÇÃO NACIONAL. Programa Nacional de Desenvolvimento Regional - PNDR. Brasília: 2004.

REIS, A. C. F. Economia criativa como estratégia de desenvolvimento: uma visão dos países em desenvolvimento / organização. - São Paulo : Itaú Cultural, 2008. 267 p.

RODRIGUES, M. M. A. Políticas Públicas. São Paulo: Publifolha, 2011. (Coleção Folha Explica).

SOUZA, T. C. A dinâmica e os efeitos de transbordamento da economia criativa no nordeste do Brasil. Ilhéus, BA: UESC, 2015. 180 f. (Dissertação de Mestrado) 
Id on Line Revista Multidisciplinar e de Psicoloqia

Id on Line Multidisciplinary and Psycology Journal

SOUZA, C. Políticas públicas: uma revisão da literatura. Scielo. Disponível em: < http://www.scielo.br/scielo.php?script=sci_arttext\&pid=S1517-45222006000200003> Acessado em 01/04/2017.

Como citar este artigo (Formato ABNT):

VALE JÚNIOR, João Sotero do; GONDIM, Ionara M. de A.; SANTOS, Juliana B. dos; NEVES, carolina M. I. N. As Políticas Públicas para o Desenvolvimento do Território Médio Rio das Contas: Potencialidades e Desafios. Id on Line Revista Multidisciplinar e de Psicologia, 2017, vol.11, n.37, p. 618-639. ISSN: 19811179.

Recebido: 21.07.2017

Aceito: 22.07.2017 